\title{
MộT SỐ NHẬn XÉT CHẨN ĐOÁN VÀ ĐIỀU TRI LÓC ĐỘNG MẠCH CHỦ TYPE A TẠI BỆNH VIỆN VIỆT ĐỨC
}

\section{TÓM TÁT:}

Muc đích: Nhận xét về chẩn đoán và điều trị lóc động mạch chủ type A tại Bệnh viện Hữu nghị Việt Đức.

Đối tượng và phuơng pháp: Mô tả 74 trường hợp được chẩn đoán lóc động mạch chủ type A tại Bệnh viện Việt Đức từ tháng 9 năm 2012 tới tháng 9 năm 2014.

Kết quả: Số bệnh nhân được phẫu thuật là 44, có 30 trường hợp không phẫu thuật. Bệnh nhân được chuyển tới bệnh viện Việt Đức muộn (trung bình 3.3 ngày). Nhiều biến chứng, bệnh phức tạp phối hợp và chi phí điều trị cao là những lý do cản trở điều trị phẫu thuật. Có 8 trường hợp mạn tính, 66 trường hợp cấp tính. Tỉ lệ tử vong chung tại bệnh viện là $43.2 \% ; 1$ tháng của nhóm phẫu thuật là $18.2 \% ; 1$ tháng của nhóm không phẫu thuật là $86.7 \%$. Chẩn đoán và điều trị thành công những thể lóc động mạch chủ type $\mathrm{A}$ ít gặp và phức tạp như bệnh nhân đã mổ tim hở, có bệnh thận nặng (chạy thận chu kỳ, hội chứng thận hư) và bệnh nhân suy chức năng thất trái nặng.

Kết luận: Bệnh nhân lóc động mạch chủ type $\mathrm{A}$ thường được chuyển đến Bệnh viện Việt Đức muộn, tỉ lệ được phẫu thuật còn hạn chế. Điều trị phẫu thuật cấp cứu làm giảm nguy cơ tử vong rõ rệt so với điều trị không phẫu thuật. Đã chẩn đoán và điều trị thành công nhiều thể ít gặp và nặng của lóc động mạch chủ type A.

\section{SUMMARY}

\section{DIAGNOSTIC AND TREATMENT OF AORTIC DISSECTION IN VIETDUC HOSPITAL}

Background: Diagnostic and early results of surgical and non-surgical type A aortic dissection in Vietduc hospital.

Materials and methods: Description of 74 cases of type A aortic dissection in Vietduc hospital from 9/2012 to $9 / 2014$.

Results: 44 of surgical treatment and 30 of nonsurgical treatment. Patient hospitalized late to Vietduc

\section{Vũ Ngoc Tü*, Nguyê̂n Hũu U'óc* *}

(3.3 days). Reasons of non-surgical treatment: late diagnostic, severe complications and expensive cost. 8 of chronic type A aortic dissections and 66 of acute type A aortic dissections. In hospital mortality: $43.2 \%$; 30 days post-operative mortality: $18.2 \%$ and 30 days non-surgical mortality: $86.7 \%$. Adapting of point of view, suture technique, CPB and ECMO technique, we have succesful diagnostic and treatment of rare and complex type $\mathrm{A}$ aortic dissections: intramural hematoma, after previous aortic valve replacement, penetrating atherosclerotic ulcer and severe left ventricle dysfunction.

Conclusion: Patient hospitalized late to Vietduc and limitation of surgical treatment for type A aortic dissection. Significant lower mortality of surgical treament of type A aortic dissection. Succesful diagnostic and treatment of rare and complex type A aortic dissections in Vietduc hospital.

\section{I- ĐẶT VẤN ĐỀ}

Phẫu thuật là biện pháp điều trị đem lại hiệu quả cho lóc động mạch chủ (LĐMC) type A(theo phân loại của Stanford). Nếu được điều trị đúng và phẫu thuật kịp thời, tỉ lệ tử vong của bệnh nhân giảm đi rất nhiều, có thể chỉ còn dưới 10\% [2]. Tại Việt Nam phẫu thuật LĐMC type A đã được thực hiện ở một số trung tâm phẫu thuật tim mạch từ khoảng hơn mười năm nay [3], [4]. Tuy nhiên để điều trị tốt bệnh lý này, đòi hỏi phải chẩn đoán đúng và chỉ định phẫu thuật ngay từ những giờ đầu tiên. Hơn nữa chi phí điều trị rất tốn kém nên nhiều khi không thể triển khai phẫu thuật, dẫn tới tỉ lệ tử vong và biến chứng còn cao. Mục tiêu của nghiên cứu là đưa ra những nhận xét về chẩn đoán và điều trị bệnh lý phức tạp này tại Bệnh viện Việt Đức.

\footnotetext{
Khoa Phẫu thuật Tim mạch và Lồng ngục - Bệnh viện Việt Đưc Người chịu trách nhiệm khoa học: PGS.TS. Nguyễn Hũu U’ớc Ngày nhận bài: 10/01/2016 - Ngày Cho Phép Đăng: 24/02/2016 Phản Biện Khoa học: PGS.TS. Đặng Ngocc Hùng
} GS.TS. Bùi Đúc Phú 


\section{PHƯƠNG PHÁP NGHIÊN CÚU}

Mô tả 74 trường hợp LĐMC type $\mathrm{A}$ được điều trị phẫu thuật và không phẫu thuật tại Bệnh viện Việt Đức từ tháng 9 năm 2012 tới tháng 9 năm 2014.

\section{Tiêu chuẩn lựa chọn:}

+ Tất cả các bệnh nhân chẩn đoán là LĐMC type A.

+ Có đầy đủ hồ sơ, bệnh án, xét nghiệm cận lâm sàng phục vụ cho nghiên cứu.

\section{KẾT QUẢ VÀ BÀN LUẬN}

\subsection{Dịch tê̂ hoc:}

Tỉ lệ nam/ nữ: 2,3 : 1

Kết quả này phù hợp với đa số các tác giả khác. Theo kết quả nghiên cứu đa trung tâm của Hagan $\mathrm{PG}$ và cs năm 2000, tỉ lệ nam chiếm $65 \%$ [5]

Thời gian chuyển viện trung bình và các nguyên nhân gây chậm trễ.

Bảng 1: nguyên nhân gây chậm trễ và thời gian chuyển viện

\begin{tabular}{|l|c|}
\hline \multicolumn{1}{|c|}{ Nguyên nhân } & N \\
\hline Không đi khám & $16(21.6 \%)$ \\
\hline $\begin{array}{l}\text { Vị trí địa lý và phương thức vận } \\
\text { chuyển không thuận lợi }\end{array}$ & $10(13.5 \%)$ \\
\hline Chẩn đoán xác định chậm & $34(46 \%)$ \\
\hline $\begin{array}{l}\text { Nơi chẩn đoán không có khả năng } \\
\text { phẫu thuật }\end{array}$ & $14(18.9 \%)$ \\
\hline
\end{tabular}

Thòi gian trung bình trước khi tới bệnh viện Việt Đức: $3.3 \pm 4.4$ (ngày) (ít nhất: 10 giờ - nhiều nhất: 21 ngày)

LĐMC type A là bệnh lí cấp cứu ngoại khoa tối cấp, nhất là type $\mathrm{A}$ cấp tính. Nếu không được điều trị phẫu thuật, bệnh này có tỉ lệ tử vong tới $50 \%$ trong 48 giờ đầu, tăng thêm $1 \%$ mỗi giờ, và tử vong tới $92 \%$ sau 1 năm [10]. Toàn bộ số bệnh nhân trong nghiên cứu đều được chuyển từ nơi khác tới Bệnh viện Việt Đức để chẩn đoán và/ hoặc phẫu thuật. Tuy nhiên thời gian trung bình bệnh nhân tới Bệnh viện Việt Đức là khoảng 3.3 ngày, lâu nhất là 21 ngày là tương đối chậm. Nguyên nhân chủ yếu là do bệnh nhân có tâm lí chủ quan, không đi khám bệnh, bệnh nhân ở các vùng địa lí xa xôi, không có khả năng chuyên sâu để chẩn đoán, nhưng cũng không thuận lợi cho công tác vận chuyển bệnh nhân. Tuy nhiên nguyên nhân chính dẫn tới việc chậm trễ lại do công tác chẩn đoán bệnh ở những cơ sở y tế đủ khả năng chuyên môn (bệnh viện tuyến tỉnh, khu vực trở lên) lại không chẩn đoán được bệnh (chiếm 46\%).

\subsection{Tuổi trung bình và tỉ lệ bệnh nhân Marfan.}

Bảng 2: Tuổi trung bình và tỉ lệ bệnh nhân Marfan

\begin{tabular}{|l|c|}
\hline \multicolumn{1}{|c|}{ Tổng số BN } & $\mathbf{7 4}$ \\
\hline Số BN Marfan & $15(20.2)$ \\
\hline Tuối TB chung & $49.8 \pm 9.5$ \\
\hline Tuối cao nhất/ thấp nhất & $78 / 20$ \\
\hline Tuối TB Marfan & $36.1 \pm 14.3$ \\
\hline
\end{tabular}

Tuổi trung bình của nghiên cứu là 49.8 tuổi. So với các nghiên cứu khác của các nước phát triển, độ tuổi này trẻ hơn. Ví dụ theo Hagan độ tuổi trung bình là 62 , còn theo Inamura tuổi trung bình là 60 . Tuy nhiên nếu so với các nước đang phát triển thì độ tuổi như vậy cũng có sự tương đồng. Ví dụ theo tác giả LiZhong Sun thì độ tuổi trung bình là 45 [5]. Có thể do nền kinh tế phát triển, chăm sóc y tế cũng hiện đại hơn nên có thể tiến hành phẫu thuật LĐMC type $\mathrm{A}$, là một phẫu thuật rất nặng cho những bệnh nhân lớn tuổi. Ngược lại ở các nước đang phát triển, như ở Việt Nam, phẫu thuật này ngoài sự rủi ro lớn, còn kèm theo chi phí kinh tế lớn cho người bệnh. Vì vậy số lượng bệnh nhân được phẫu thuật LĐMC type $\mathrm{A}$ ở người lớn tuổi còn nhiều hạn chế.

Trong nghiên cứu của chúng tôi, có tới 15 bệnh nhân (chiếm 20.2\%) bệnh nhân có kiểu hình của hội chứng Marfan. So với các nghiên cứu khác, đây là một tỉ lệ khá cao (của Hagan chỉ là 6.7\%). Đối với các bệnh nhân Marfan, tuổi bị LĐMC cũng trẻ hơn nhiều so với tuổi trung bình chung, và như vậy cũng sẽ là một nguyên nhân làm cho tuổi trung bình của nghiên cứu thấp đi nhiều.

\subsection{Triệu chứng lâm sàng:}

Bảng 3: Triệu chúng lâm sàng truớc khi điều trị phẫu thuật

\begin{tabular}{|l|c|c|}
\hline \multicolumn{1}{|c|}{ Triệu chứng } & N & \% \\
\hline THA & 63 & 85.4 \\
\hline Chênh lệch HA các chi & 26 & 35.4 \\
\hline Tiếng thổi tâm thu & 21 & 28.2 \\
\hline Chèn ép tim & 12 & 15.8 \\
\hline Thiếu máu tạng - viêm phúc mạc & 9 & 12.1 \\
\hline Sốc mất máu nặng & 16 & 21.6 \\
\hline
\end{tabular}


Trong số các triệu chứng lâm sàng, triệu chứng đau ngực và và tăng huyết áp có tỉ lệ cao nhất. Mặc dù không phải là triệu chứng đặc hiệu, nhưng theo nhiều tác giả, tăng huyết áp là yếu tố nguy cơ lớn nhất gây LĐMC [6]. Huyết áp tăng càng cao thì tỉ lệ LĐMC càng cao, đặc biệt là với tăng huyết áp ác tính. Trong nghiên cứu của chúng tôi, ngoại trừ các bệnh nhân Marfan, các bệnh nhân khác đều có tăng huyết áp, và phần lớn những bệnh nhân này không được điều trị khống chế tốt huyết áp thường xuyên.

Cũng đáng lưu ý là trong số này, có 12 bệnh nhân khi vào viện đã có triệu chứng chèn ép tim. Tuy nhiên, các trường hợp này áp lực tĩnh mạch trung ương không quá cao, bởi vì chủ yếu là do máu thấm qua thành $\mathrm{ĐMC}$ vào khoang màng tim chứ không phải là do vỡ ĐMC. Các biến chứng nặng khác của LĐMC là sốc mất máu nặng do vỡ ĐMC và thiếu máu tạng ổ bụng muộn - viêm phúc mạc gây suy đa tạng, nhóm này có 9 bệnh nhân, đều không điều trị phẫu thuật. Lý do chính là nguy cơ điều trị phẫu thuật và chi phí là rất lớn nên dù chúng tôi có đưa ra chỉ định nhưng gia đình và bệnh nhân cũng từ chối phẫu thuật.

\subsection{Triệu chứng cận lâm sàng}

Bảng 4: Các triệu chứng cận lâm sàng trước phẫu thuật

\begin{tabular}{|c|l|c|c|}
\hline \multicolumn{2}{|c|}{ Chỉ số } & N & \% \\
\hline \multirow{3}{*}{$\begin{array}{c}\text { Vị trí } \\
\text { lóc }\end{array}$} & ĐMC lên + quai & 4 & 5.4 \\
\cline { 2 - 4 } & ĐMC ngực + bụng & 68 & 91.8 \\
\cline { 2 - 4 } & Các mạch cảnh & 43 & 58.1 \\
\cline { 2 - 4 } & Các mạch tạng & 12 & 16.2 \\
\hline \multirow{2}{*}{$\begin{array}{c}\text { Các thể } \\
\text { đặc biệt }\end{array}$} & Loét thủng do xơ vữa & 1 & - \\
\cline { 2 - 4 } & Máu tụ trong thành & 5 & - \\
\cline { 2 - 4 } & Đã mố tim hở & 2 & - \\
\hline
\end{tabular}

Về vị trí LĐMC, chỉ có 2 trường hợp lóc đơn thuần tại ĐMC lên, còn lại đại đa số lóc ở toàn bộ ĐMC. Kết quả này cũng phù hợp với nghiên cứu của Robert WC [6]. Tỉ lệ các động mạch cảnh bị lóc cũng khá cao $(33.3 \%)$.

Biện pháp chính để chúng tôi chẩn đoán xác định LĐMC là chụp cắt lớp vi tính đa dãy có tiêm thuốc cản quang và dựng hình. Phương pháp này có độ nhậy đạt $83-94 \%$, độ đặc hiệu là $87-100 \%$ đối với chẩn đoán LĐMC. Vì vậy, để chẩn đoán xác định được
LĐMC type A với vách nội mạc phân chia lòng thật, lòng giả như kinh điển là không quá khó. Tuy nhiên để có thể đưa ra chỉ định sớm nhất và hiệu quả phẫu thuật cao nhất, chúng tôi cố gắng chẩn đoán các thể bệnh ít gặp và là những giai đoạn sớm của $\mathrm{LĐMC}$, chưa hình thành lòng giả, lòng thật rõ ràng. Đó là các thể: loét thủng do xơ vữa, máu tụ trong thành.

3.5. Kĩ thuật vận hành máy tim phổi nhân tạo và các phương pháp bảo vệ não

Bảng 5: Vận hành máy tim phổi nhân tạo trong phẫu thuật LĐMC type A

\begin{tabular}{|c|l|c|c|}
\hline \multicolumn{2}{|c|}{ Chỉ số } & N & \% \\
\hline \multirow{2}{*}{$\begin{array}{c}\text { Dung dịch } \\
\text { bảo vệ tim }\end{array}$} & Máu ấm & 7 & 15.9 \\
\cline { 2 - 4 } & Custodiol lạnh & 37 & 84.1 \\
\hline \multirow{2}{*}{$\begin{array}{c}\text { Vị trí canuyn } \\
\text { ĐM }\end{array}$} & ĐM nách & 34 & 77.4 \\
\cline { 2 - 4 } & ĐM đùi & 4 & 9 \\
\cline { 2 - 4 } & ĐM nách + đùi & 6 & 13.6 \\
\hline \multirow{2}{*}{$\begin{array}{c}\text { Tưới máu } \\
\text { não }\end{array}$} & $\begin{array}{c}\text { Chọn lọc (riêng } \\
\text { các mạch cảnh) }\end{array}$ & 11 & 25 \\
\cline { 2 - 4 } & Không chọn lọc & 33 & 75 \\
\hline
\end{tabular}

Đối với những bệnh nhân LĐMC type $\mathrm{A}$, thường không thể đặt trực tiếp canul vào ĐMC lên. Vì vậy, hai vị trí thường được sử dụng thay thế là động mạch đùi và động mạch nách. Tại vị trí động mạch đùi, chúng ta có thể đặt trực tiếp canul một cách nhanh chóng và dễ dàng. Tuy nhiên, đã có những nghiên cứu tổng kết cho rằng đặt canul động mạch tại vị trí này có một số nguy cơ: 1) làm cho tình trạng tổn thương mạch nặng hơn, vì đại đa số các trường hợp LĐMC type $\mathrm{A}$ đều kèm theo lóc tới hệ thống động mạch chậu. 2) có thể gây hậu quả thiếu máu tạng do tưới máu ngược vào lòng giả [7]. Vì vậy, xu hướng hiện nay là sử dụng canul động mạch nách để đảm bảo tưới máu xuôi dòng sinh lý, qua đó hạn chế tối thiểu nguy cơ thiếu máu tạng [8]. Chúng tôi sử dụng phương pháp đặt canul động mạch nách qua một cầu nối tận bên bằng mạch nhân tạo Dacron $8 \mathrm{~mm}$, ngoài đảm bảo tưới máu cơ thể xuôi dòng, còn có tác dụng giảm thiểu tưới máu chi trong quá trình phẫu thuật kéo dài.

Khi không phải can thiệp vào các nhánh của quai ĐMC, chúng tôi không sử dụng tưới máu riêng các 
mạch cảnh. Trong trường hợp bắt buộc phải can thiệp vào quai (thay toàn bộ quai hay bán quai), cần phải tưới máu riêng rẽ qua động mạch nách phải (hoặc động mạch cảnh phải) và động mạch cảnh trái, có đường theo dõi áp lực riêng kèm theo. Can thiệp trên các nhánh của quai ĐMC có nguy cơ tử vong và biến chứng cao hơn, nên thay vì quan điểm lấy bỏ triệt để ĐMC bị lóc, quan điểm hiện nay của chúng tôi là thay ĐMC chủ lên cho mọi trường hợp không có lỗ rách nội mạc lớn liên quan tới các nhánh này.

Với đại đa số các trường hợp không phải thay quai ĐMC, bệnh nhân được hạ nhiệt độ vừa (28 $32^{\circ} \mathrm{C}$ ). Trong trường hợp phải thay toàn bộ quai, thân nhiệt được hạ sâu hơn $\left(25^{\circ} \mathrm{C}\right)$, kết hợp với tưới máu nửa dưới cơ thể bằng canul động mạch đùi và đặt sonde Foley ĐMC xuống. Chỉ trong những trường hợp không thể bảo đảm phẫu trường rộng rãi, rõ ràng thì mới phải dung tới phương pháp hạ thân nhiệt sâu (tới $18-20^{\circ} \mathrm{C}$ ) kèm ngừng tuần hoàn. Việc chỉ hạ nhẹ - vừa thân nhiệt sẽ giúp thời gian phẫu thuật nhanh hơn, nhưng quan trọng hơn là giúp bệnh nhân tránh được các rối loạn toàn thân nặng nề sau mổ.

3.6. Tỉ lệ tử vong sau điều trị phẫu thuật và điều trị không phẫu thuật

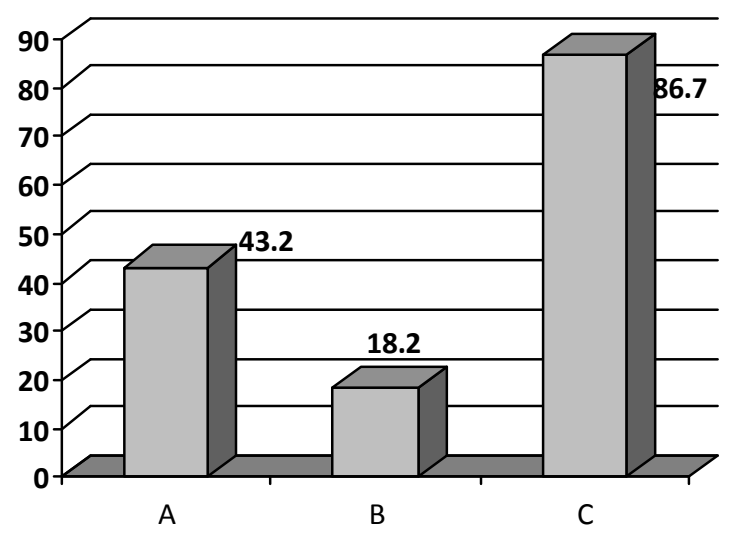

Hình 2: Các tỉ lệ tử vong sau điều trị lóc ĐMC type A

A: tư vong chung tại viện; $B$ : 1 tháng - nhóm mổ ;

C: 1 tháng - nhóm không mổ

Tỉ lệ tử vong sau phẫu thuật 1 tháng là $18.2 \%$, nằm trong phạm vi tỉ lệ tử vong $15-25 \%$ theo nhiều tác giả khác thế giới [3], [5]. Hiện nay đã có những trung tâm hạ tỉ lệ tử vong của phẫu thuật LĐMC type
A còn dưới $10 \%$. Tỉ lệ tử vong nếu không được phẫu thuật là $86.7 \%$, cao hơn nhiều tỉ lệ tử vong sau phẫu thuật. Tỉ lệ tử vong 24 giờ đầu của LĐMC cách đây 50 năm được thông báo là $21 \%$. Trong 30 ngày, chỉ $8 \%$ trong số còn lại sống sót. Và con số này chỉ là $2 \%$ sau 1 năm. 10 năm sau, tỉ lệ tử vong $48 \mathrm{~h}$ đầu vẫn còn là $50 \%$ hoặc $1 \%$ mỗi giờ. Có tới $20 \%$ chết trước khi tới bệnh viện. thậm chí trong nghiên cứu gần đây, có tới $68 \%$ bệnh nhân tử vong $48 \mathrm{~h}$ đầu, hay $1.4 \%$ mỗi giờ trong một nghiên cứu kéo dài 27 năm. Nguyên nhân tử vong chính là vỡ ĐMC trong khoảng $80 \%$ trường hợp [10].

Trong số những bệnh nhân không được phẫu thuật, đa phần là các trường hợp đến muộn có các biến chứng nặng (vỡ ĐMC, hội chứng thiếu máu tạng nặng ...), trên những bệnh nhân cao tuổi có nhiều bệnh khác phối hợp. Khi chỉ định phẫu thuật cho những bệnh nhân, thường gia đình bệnh nhân sẽ từ chối phẫu thuật. Thêm một lí do nữa để bệnh nhân và gia đình bệnh nhân không đồng ý phẫu thuật là chi phí cho phẫu thuật này vẫn còn rất cao so với thu nhập của đại bộ phận người dân Việt Nam.Trong nghiên cứu này có tới 14/38 trường hợp không được phẫu thuật, chỉ 2 người còn sống sau 1 tháng, $2 / 3$ số này chết vì vỡ, và $1 / 3$ còn lại do thiếu máu tạng ổ bụng. Do đó, điều rất quan trọng đối với bệnh lí này là cần phải chẩn đoán được sớm ngay từ những giờ đầu tiên, sau đó càng sớm càng tốt, phải chỉ định phẫu thuật thì mới cứu sống được bệnh nhân.

\subsection{Kết quả điều trị phẫu thuật}

Bảng 6: Tử vong và mổ lại sau phẫu thuật LDMC type $A$

\begin{tabular}{|c|c|c|}
\hline Biến chứng & Nguyên nhân & N \\
\hline \multirow{2}{*}{ Mổ lại $(2=4.5 \%)$} & Chảy máu & 2 \\
\cline { 2 - 3 } & Viêm xương ức & 1 \\
\hline \multirow{2}{*}{ Tử vong $(8=18.2 \%)$} & Suy đa tạng & 4 \\
\cline { 2 - 3 } & Nhiễm trùng & 1 \\
\hline
\end{tabular}

Một trong các biến chứng thường gặp nhất của phẫu thuật lóc ĐMC type $\mathrm{A}$ là chảy máu sau mổ. Nguyên nhân là do phẫu thuật kéo dài, trong tình 
trạng cấp cứu, thêm vào đó là có thể phải hạ thân nhiệt sâu để có thể ngừng tuần hoàn, dẫn tới rối loạn đông máu sau mổ. Để giảm thiểu nguy cơ chảy máu, hiện nay chúng tôi cải tiến thêm về mặt kĩ thuật khâu các miệng nối ĐMC, theo nguyên tắc đưa hoàn toàn mạch nhân tạo vào lòng ĐMC thật để giảm lực tác động trực tiếp của dòng máu lên miệng nối. Theo nhiều nghiên cứu, các biến chứng chủ yếu của phẫu thuật LĐMC type A dẫn tới mổ lại là chảy máu, viêm xương ức [9], [10]. Trong nghiên cứu này, chúng tôi chỉ có 2 trường hợp phải mổ lại vì chảy máu, trong đó 1 trường hợp phải dùng chống đông liều cao do phải sử dụng ECMO ngay sau mổ. Trường hợp này bị bỏ sót thương tổn lóc gây tắc động mạch vành phải nhiều ngày từ tuyến trước, vào viện bệnh nhân suy tim nặng, EF 37\%. Cũng chính bệnh nhân này phải mổ lại viêm xương ức 1 lần nữa, là trường hợp viêm xương ức duy nhất trong nghiên cứu này. Bệnh nhân xuất viện với tình trạng sức khỏe tốt.

\section{KẾT LUẬN}

Phẫu thuật LĐMC type A đã được triển khai như một cấp cứu thường qui ở bệnh viện Việt Đức. Tuy nhiên vẫn còn nhiều bệnh nhân LĐMC type $\mathrm{A}$ chưa được phẫu thuật, chủ yếu do chẩn đoán muộn, người bệnh già yếu, có nhiều bệnh kết hợp dẫn tới tỉ lệ tử vong chung còn cao. Hiện nay chúng tôi đã áp dụng nhiều thay đổi về mặt quan điểm và kĩ thuật để một mặt có thể chẩn đoán và điều trị nhiều thể bệnh sớm, mặt khác có thể phẫu thuật thành công các thể bệnh nặng của LĐMC type A.

\section{TÀI LIỆU THAM KHẢO}

1. Wheat MWJ, Wilson JR, Bartley TD: Successful replacement of the entire ascending aorta and aortic valve. JAMA 1964; 188:717.

2. Cachera JP, Vouhe PR, Loisance DY, Menu P, Poulain H, Bloch G, Vasile N, Aubry P and Galey JJ. Surgical management of acute dissections involving the ascending aorta. Early and late results in 38 patients
3. Nguyễn Thái An, Phạm Thọ Tuấn Anh. Đánh giá kết quả sớm phẫu thuật phình và bóc tách động mạch chủ lên và quai. Tạp chí Y học Việt Nam, 11/2010, tập 375: trang $77-82$.

4. Nguyễn Công Hựu, Đoàn Quốc Hưng, Dương Đức Hùng, Nguyễn Hữu Ước, Lê Ngọc Thành và CS. Kết quả phẫu thuật bệnh lí động mạch chủ ngực tại bệnh viện Việt Đức. Bệnh viện 103 - Học viện quân y: Hội nghị quốc tế Việt - Đức Những tiến bộ trong phẫu thuật và can thiệp tim mạch, 3/2010: 24-31.

5. Hagan PG, Nienaber CA, Isselbacher EM, et al. The International Registry of Acute Aortic Dissection (IRAD): new insights into an old disease. JAMA. Feb 16 2000;283(7):897-903.

6. Roberts WC. Aortic dissection: anatomy, consequences, and causes. Am Heart J. 1981 Feb;101(2):195-214.

7. Laas J, Heinemann M, Schaefers HJ, Daniel W, Borst HG. Management of thoracoabdominal malperfusion in aortic dissection. Circulation. 1991 Nov;84(5 Suppl):III20-4

8. Van Arsdell GS, David TE, Butany J. Autopsies in acute type A aortic dissection. Surgical implications. Circulation. 1998 Nov 10;98(19 Suppl):II299-302; discussion II302-4.

9. Chiappini B et al. Early and late outcomes of acute type A aortic dissection: analysis of risk factors in 487 consecutive patients. Eur Heart J (January 2005) 26(2): 180-18

10. Shiono $M$ et al. Surgical results in acute type A aortic dissection. Ann Thorac Cardiovasc Surg 2005; 11: 29-34 